\title{
Designing an Intelligent Maximum Power Point Tracking (MPPT) for a Rooftop Solar Array
}

\author{
Afshin Balal ${ }^{1}$ | Shahab Balali ${ }^{2}$ \\ ${ }^{1}$ Electrical and Computer Engineering Department, Texas Tech University, Lubbock, Texas, USA \\ 2Electrical and Computer Engineering Department, Azad University of Tehran, Tehran, Iran
}

To Cite this Article

Afshin Balal \& Shahab Balali. Designing an Intelligent Maximum Power Point Tracking (MPPT) for a Rooftop Solar Array. International Journal for Modern Trends in Science and Technology 7, 133-138 (2021).

\section{Article Info}

Received on 18-April-2021, Revised on 11-May-2021, Accepted on 19-May-2021, Published on 22-May-2021.

\section{ABSTRACT}

By considering the limitation of the size of houses, the permanent inaccessibility of the solar radiation energy, and also the low efficiency of solar cells, a PV system requires the maximum power point tracking(MPPT). The main issue with using solar cells is to reach its maximum power, which is intensified by change in the temperature and radiation. In this paper, among MPPT methods, the Perturb and Observe (P\&O) method, has been designed which has high reliability and traceability. However, due to the output power oscillation around the operating point in $\mathrm{P} \& O$ method, an optimization fuzzy/bee algorithm is used for maximum power point tracking so that without the need for temperature and light sensors, reduction of output power oscillations can be achieved. Simulation results indicate that by using the fuzzy/ bee method, in addition to reducing the fluctuation around the operating point, the speed of reaching to the optimal point is maximized.

KEYWORDS: Maximum Power Point Tracking (MPPT), Rooftop Solar Array, Fuzzy / Bee Algorithm.

\section{INTRODUCTION}

Nowadays, consumption of electrical energy continues to increase rapidly and much more than suppling part of it, which leads to much hours of peak demand especially in the summer, when people utilize much more energy for cooling their places. The increasing of consumption of electrical power is most commonly for lighting and appliances of building, processes of producing materials in industrial part, and more using of electrical cars. Despite the overburdened grids in most of the countries, there is not much demand of solar energy systems even in developed countries. The three important reasons for this issue are: discontinuous availability of sun radiation in the cloudy days and night time, expensive cost, and lack of awareness of people about the potential solar energy[1]-[2]. There are two main methods for maximizing power. First method is a control system, which requires mechanical mechanisms in order to determine the angle of the sun and the second method is MPPT. In a PV system, as the voltage and current characteristics of the solar arrays are nonlinear and affected by sun radiation and temperature, maximum power point tracking is inevitable in order to extract maximum power from solar arrays[3]-[4]. MPPT needs sensors for measuring voltage and current, a DC-DC converter for converting the solar output voltage to the required voltage of the PV system, and the controller.

\section{CURRENT-VOLTAGE CHARACTERISTIC OF SOLAR ARRAY}

Figure 1, represents a one-diode equivalent circuit of a solar cell. Solar arrays are comprised of a series and parallel combination of these cells [5]. 


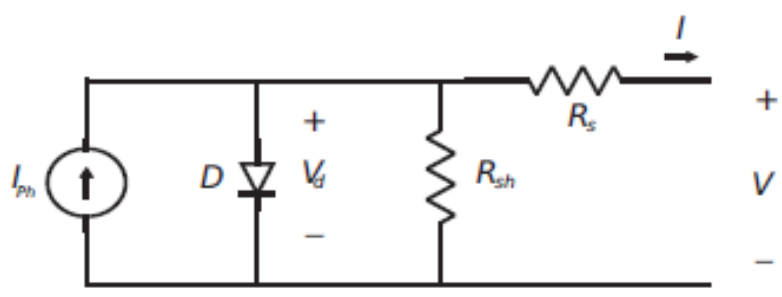

Figure 1: An equivalent circuit of a solar cell

Considering the model (Fig. 1), current - voltage characteristic of a solar cell is expressed with the help of following relations:

$\mathrm{I}=\mathrm{N}_{P} I_{P H}-N_{P} I_{S}\left[\left(\frac{q\left(\frac{V}{N_{S}}+\frac{I R_{S}}{N_{P}}\right)}{K T A}\right)-1\right]-\frac{\left(\frac{N_{P} V}{N_{S}}+I R_{S}\right)}{R_{S H}}(1)$

In the above relation, $R_{S}$ and $R_{S H}$ are the series and parallel resistance of the cell, I and V are the current and the output voltage of the solar cell, $I_{S}$ is the diode saturation current, $N_{S}$ and $N_{P}$ are the number of series and parallel cells, respectively, $\mathrm{T}$ is the cell temperature in terms of Kelvin, and $\mathrm{A}$ is the diode ideal coefficient, $\mathrm{K}$ is Boltzmann's constant in units of Kelvin (K) is equal to $K=1.23 \times 10^{23}$ and $q=1.6 \times 10^{-19}$ is the charge of an electron in units of coulomb $(\mathrm{C})$, and $I_{P H}$ is the photovoltaic current.
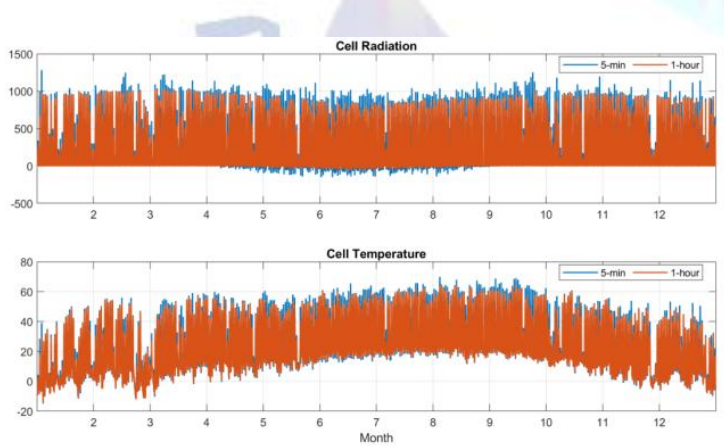

Figure 2: Radiation and cell temperature variations

As shown in Fig. 2, the solar cell characteristic V-I is influenced by the two factors of radiation and temperature. This dependence on temperature and radiation is modeled with the following relations.

$$
\begin{aligned}
& I_{P H}=\left[I_{S C}+K\left(T-T_{R E F}\right)\right] \frac{S}{1000} \\
& I_{R S}=\frac{I_{S C}}{\left[\exp \left(\frac{q V_{O C}}{N_{S} K A T}\right)-1\right]} \text { (3) }
\end{aligned}
$$

$$
I_{S}=I_{R S}\left(\frac{T}{T_{R E F}}\right)^{3} \exp \left[\frac{q E_{g}\left(\frac{1}{T_{r e f}}-\frac{1}{T}\right)}{K A}\right]
$$

In relation (2 and 3$), I_{S C}$ is the short-circuit current of the cell, $T$ is the cell temperature in units of Kelvin and $T_{r e f}=273$, and $S$ is the amount of radiation in units of watts per square meter and $S_{r e f}=1000 \frac{\mathrm{w}}{\mathrm{m}^{2}}$, and $K$ is the Boltzmann constant and is equal to $K=1.23 \times 10^{23}$, the charge of an electron in units of coulomb (C) is equal to $q=1.6 \times 10^{-19}$ and $E_{g} \succ 0.1 \mathrm{ev}$, is the band of energy in terms of electron volts.

In relation (4), $I_{S C}$ is the short-circuit current and $V_{O C}$ is the open circuit voltage, $N_{S}$ is the number of series cells [6]-[7].

\section{DC-DC BUCK CONVERTER}

In order to transfer the maximum power from solar cell to the load, it is necessary to select the best converter. For this reason, DC-DC converter efficiency is very important. The efficiency of the buck converter is greater than both boost and buck-boost converter[8]-[9]. So, it seems that the choice of a buck converter is a desirable choice. For deigning a buck converter, the value of the inductor and capacitor is obtained as follows:

$$
\begin{aligned}
& L=\frac{\mathrm{v}_{\text {out }}(1-D)}{f_{s} \Delta I} \\
& C=\frac{\Delta I}{8 f_{s} \Delta V}
\end{aligned}
$$

Which Delta I is the output current ripple and Delta $\mathrm{V}$ is the output voltage ripple.In Fig. 3, simulation of the DC- DC buck converter is shown.

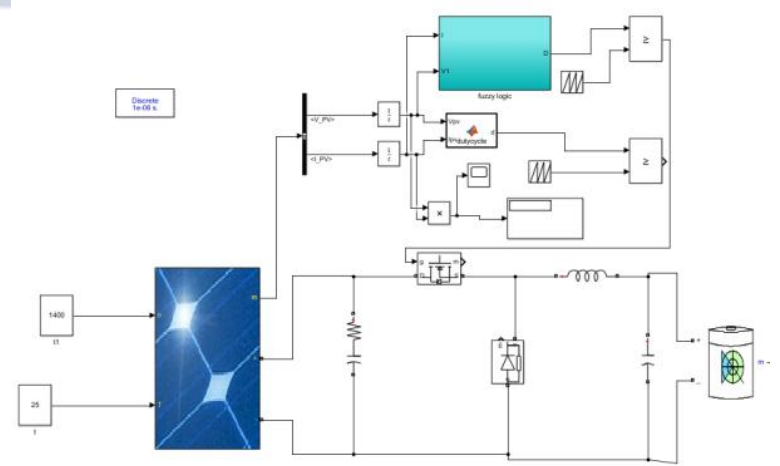

Figure 3: Simulation of a DC-DC Converter 


\section{MAXIMUM POWER POINT TRACKING (MPPT)}

voltage characteristic of non-linear solar arrays is influenced by radiation and temperature variations. To overcome this problem, it is necessary to provide a Maximum Power Point (MPPT) in order to get maximum power. Fig. 4, shows the MPP diagram.

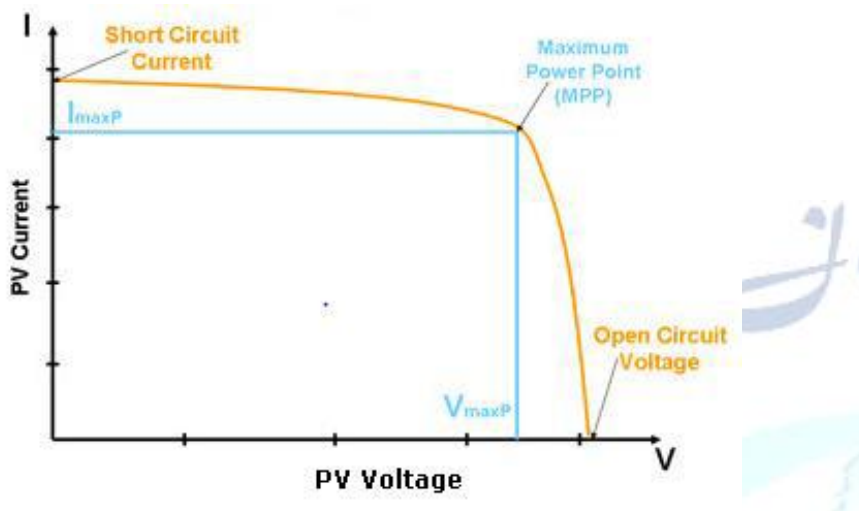

Figure 4: Maximum MPP power point diagram

As shown in Figure 5, to match the load with the solar array, in order to absorb the maximum power, the buck converter is used as a power processor [10].

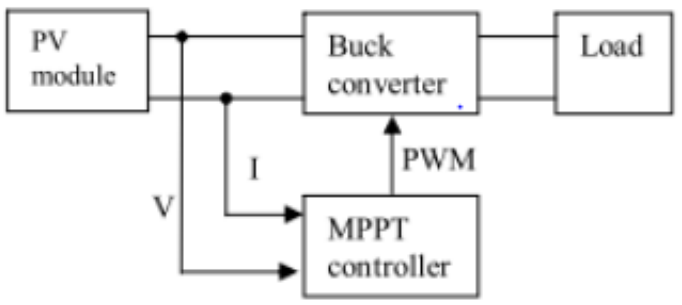

Figure 5: Block diagram of the MPPT controller

\section{PERTURB AND OBSERVATION METHOD (P\&O)}

As shown in Figure 6, in this method, it can be shown that the ratio of $\frac{d p}{d v}$ equals zero at the maximum power point and before this point, this value is positive and after it becomes negative. If $\frac{d p}{d v}$ is positive, in the same way, it continues until it $d v$

reaches a point where $\frac{d p}{d v}$ is zero, and if it is negative, it should continue in the opposite direction until it reaches the desired point. The $\mathrm{P} \&$ $\mathrm{O}$ method is the most commonly used peak power point tracker control algorithm and has two main aspects in selecting MPPT methods which they are simplicity and accurate tracking [11].

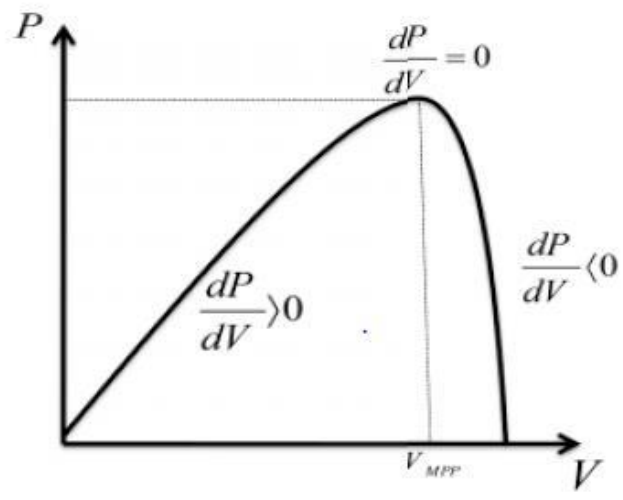

Figure 6: The effect of operating point changes to achieve the optimal point

\section{FUZZY/BEE CONTROLLER DESIGN}

Fuzzy methods are based on fuzzy logic and recently are used to solve control problems. Fuzzy logic control provides the ability to perform non-linear calculations for inaccurate inputs and is very suitable for various climate changes. Using fuzzy algorithms, without any dependence on the physical parameters of solar cells and without the need for temperature and light intensity sensors just by proper switching, it is possible to reduce power losses. The process of fuzzy logic control includes Fuzzification, Execution of all applicable rules in the rule base, and De-fuzzification. The first part is fuzzification, which converts input variables with true values into a fuzzy set, the second part is called the fuzzy inference engine, which states fuzzy IF-THEN rules, and the third part is De-fuzzification, which converts a fuzzy set to a real variable [12]-[13].

To design a fuzzy controller and to select fuzzy rules, there should be a complete understanding of the photovoltaic system's behavior. According to Fig. 4 , the maximum power point in the diagram has an important property of $\frac{d p}{d v}=0$. Also, the voltages of the points having the property of $\frac{d p}{d v} \succ 0$ , have less than the voltage of the optimal point (MP), and the points with the property of $\frac{d p}{d v} \prec 0$ have more than the voltage of the optimal point (MP). In this paper, the above-mentioned behavioral property will be used to find the maximum power point. For this purpose, following variables are generated: 
$E(t)=\frac{P_{p v}(t)-P_{p v}(t-1)}{V_{p v}(t)-V_{p v}(t-1)}$

$$
C E(t)=E(t)-E(t-1)
$$

In relation (7 and 8$), P(t)$ and $V(t)$ are the instantaneous power and voltage values, respectively. In this paper, the fuzzy controller input $E(t)$ and $C E(t)$, and the output is the pulse signal. Variable $E(t)$ represents the variation of power to voltage variations and $C E(t)$ represents the variation rate of $E(t)$, these variables will be available to the fuzzy inference machine after fuzzification so that the fuzzy variable $C D(t)$, which is equal to $C D(t)=D(t)-D(t-1)$ can be determined[14]

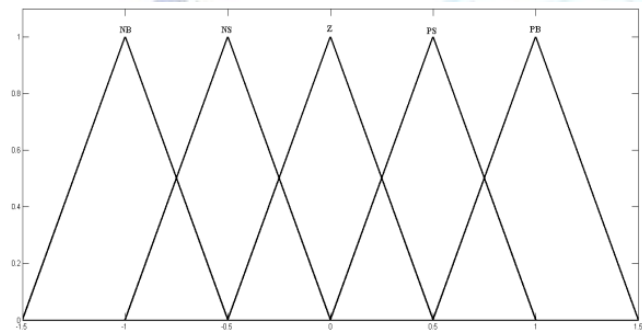

A

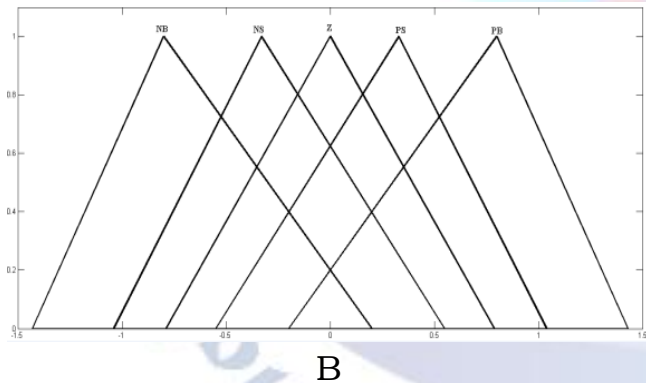

Figure 7: Membership Functions, A: Membership functions of inputs E \& CE, B: Fuzzy membership functions optimized with the Bee algorithm with 5 membership functions

By applying this optimized function to the photovoltaic (PV) system, a new method is obtained which in comparison with $\mathrm{P} \& \mathrm{O}$ and fuzzy methods, improvement of output power can easily be seen. In this system, the triangular membership function has been used for both the input and the output of the system. the Mamdani inference engine, the center average defuzzifier, and the singleton fuzzifier has been used [15]. According to Figure 7, at the beginning, the different input levels are defined so that these levels should fully cover the variation range. As table 1 indicates there is 25 fuzzy rules based.

Table 1: fuzzy rule base

\begin{tabular}{|c|c|c|c|c|c|}
\hline $\mathbf{d E}$ & NB & NS & Z & PS & PB \\
\hline NB & NB & NB & NB & Z & Z \\
\hline NS & NS & NS & NS & Z & Z \\
\hline Z & NS & Z & Z & Z & PS \\
\hline PS & Z & Z & PS & PS & PS \\
\hline PB & Z & Z & PB & PB & PB \\
\hline
\end{tabular}

Therefore, it fully covers five variables including negative big (NB), negative small (NS), ZE (zero), PS (positive small), PS (positive small), PB (positive big). In this paper we consider a small solar PV system and also with the bee algorithm, which the number of bees is 200 and also the minimum of iteration is $300[16]$.

\section{SIMULATION RESULTS}

In this paper, increment-decrement step size in the $\mathrm{P} \& \mathrm{O}$ algorithm is considered 0.01 . As shown in Figure2, initially, controller's response is investigated with regard to radiation variations. For this purpose, it is assumed that the moment, In Fig 8, Fig 9, and Fig 10, the output power of solar arrays is simulated using the $\mathrm{P} \& \mathrm{O}$, fuzzy algorithms, and fuzzy/bee algorithm. It is obvious that there is fewer oscillation in the fuzzy system which based on this, the maximum output power in the fuzzy method is more than $\mathrm{P} \& \mathrm{O}$ method. Also, in the fuzzy/bee method, fuzzy membership functions are optimized by the bee colony optimization algorithm so that the output power in fuzzy/bee algorithm is more than fuzzy method.

Table 2: The amount of output power with three different sun radiations in the LEO satellite

\begin{tabular}{|l|l|l|l|}
\hline & P\&O & Fuzzy & Fuzzy/bee \\
\hline $\begin{array}{l}\text { Output } \\
\text { power (w) at } \\
\text { radiation of } \\
1000 w / m 2\end{array}$ & 285.4 & 305.1 & 310.35 \\
\hline
\end{tabular}

As it is indicated in table 2 , the output power in above three different methods is different. 


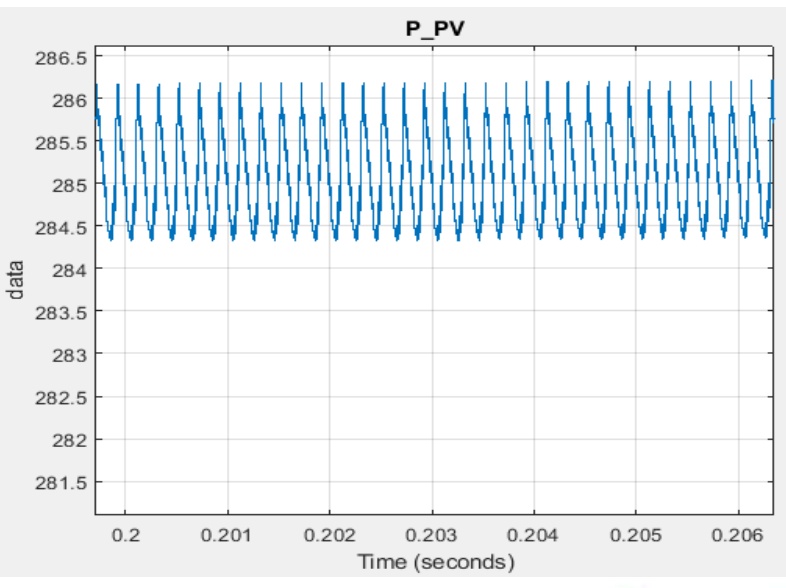

Figure 8: simulation of output power with $\mathrm{P} \& \mathrm{O}$ algorithm at radiation of $1000 \mathrm{w} / \mathrm{m} 2$

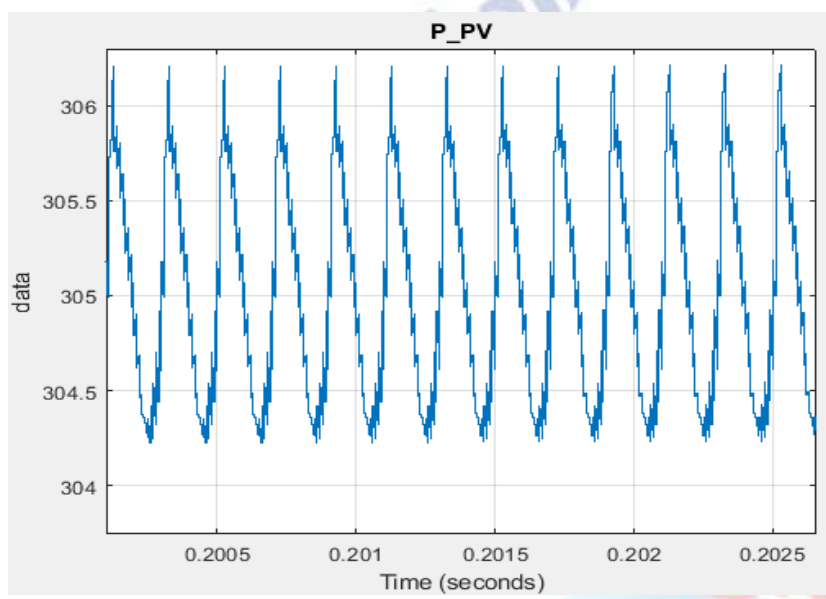

Figure 9: simulation of output power with fuzzy logic algorithm at radiation of $1000 \mathrm{w} / \mathrm{m} 2$

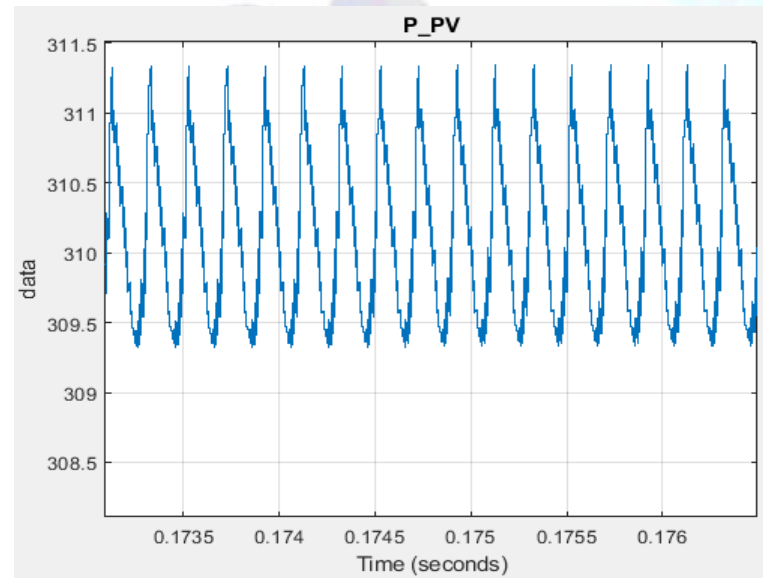

Figure 10: simulation of output power with fuzzy/bee algorithm at radiation of $1000 \mathrm{w} / \mathrm{m} 2$

\section{CONCLUSION}

In this paper, a controller based on the theory of fuzzy sets has been introduced which has the capability to track the maximum power of solar arrays under different conditions of temperature and radiation intensity. The advantage of the fuzzy controller is the independency on the physical parameters of the solar array. With such an advantage, there is no need to temperature and light sensors, and can be used in a variety of photovoltaic systems. Therefore, the maximum power point by using the $\mathrm{P} \& \mathrm{O}$ algorithm and the fuzzy method has been presented. Simulation results show that by proper switching and using fuzzy algorithms, reduction of output power oscillations and hence power losses can be achieved. However, the disadvantage of the fuzzy method is lower speed in reaching the optimal point of maximum power. So, to solve this problem, fuzzy membership functions are optimized by the bee colony optimization algorithm which in addition to reducing the output power oscillations around the operating point, the speed of reaching to the optimal point is maximized.

\section{REFERENCES}

[1] "India's economic activity almost at pre-lockdown levels but Covid looms: Nomura"Coria, G., F. Penizzotto, and R. Pringles, Economic Analysis of Rooftop Solar PV Systems in Argentina. IEEE Latin America Transactions, 2020. 18(01): p. 32-42.

[2] Shah, P. and B. Singh, Adaptive observer based control for roof-top solar PV system. IEEE Transactions on Power Electronics, 2019. 35(9): p. 9402-9417.

[3] Femia, N., et al., Optimization of perturb and observe maximum power point tracking method. IEEE transactions on power electronics, 2005. 20(4): p. 963-973.

[4] Alam, M.S., M. Azeem, and A.T. Alouani, Modified queen-bee algorithm-based fuzzy logic control for real-time robust load matching for a solar PV system. IEEE Transactions on Sustainable Energy, 2013. 5(2): p. 691-698.

[5] Breitenstein, O., An alternative one-diode model for illuminated solar cells. IEEE Journal of Photovoltaics, 2014. 4(3): p. 899-905.

[6] Bollipo, R.B., S. Mikkili, and P.K. Bonthagorla, Hybrid, optimal, intelligent and classical PV MPPT techniques: A review. CSEE Journal of Power and Energy Systems, 2020. 7(1): p. 9-33.

[7] López-Lapeña, O., M.T. Penella, and M. Gasulla, A new MPPT method for low-power solar energy harvesting. IEEE Transactions on industrial electronics, 2009. 57(9): p. 3129-3138.

[8] Stanzione, S., et al., A high voltage self-biased integrated DC-DC buck converter with fully analog MPPT algorithm for electrostatic energy harvesters. IEEE journal of solid-state circuits, 2013. 48(12): p. 3002-3010

[9] Ayop, R. and C.W. Tan, Rapid prototyping of photovoltaic emulator using buck converter based on fast convergence resistance feedback method. IEEE Transactions on Power Electronics, 2018. 34(9): p. 8715-8723.

[10] Wilamowski, B.M. and X. Li. Fuzzy system based maximum power point tracking for PV system. in IEEE 2002 28th Annual Conference of the Industrial Electronics Society. IECON 02. 2002. IEEE.

[11] Sharma, D. and G. Purohit. Advanced perturbation and observation $(\mathrm{P} \& \mathrm{O})$ based maximum power point tracking (MPPT) of a solar photo-voltaic system. in 2012 IEEE 5th India International Conference on Power Electronics (IICPE). 2012. IEEE. 
[12] Moaveni, B., F.R. Fathabadi, and A. Molavi, Supervisory predictive control for wheel slip prevention and tracking of desired speed profile in electric trains. ISA transactions, 2020. 101: p. 102-115.

[13] Moaveni, B., F. Rashidi Fathabadi, and A. Molavi, Fuzzy control system design for wheel slip prevention and tracking of desired speed profile in electric trains. Asian Journal of Control, 2020.

[14] Balal, A. and M. Murshed, Implementation and comparison of Perturb and Observe, and Fuzzy Logic Control on Maximum Power Point Tracking (MPPT) for a Small Satellite. Journal of Soft Computing and Decision Support Systems, 2021. 8(2): p. 14-18.

[15] Kottas, T.L., Y.S. Boutalis, and A.D. Karlis, New maximum power point tracker for PV arrays using fuzzy controller in close cooperation with fuzzy cognitive networks. IEEE Transactions on Energy conversion, 2006. 21(3): p. 793-803.

[16] Sundareswaran, K., et al., Enhanced energy output from a PV system under partial shaded conditions through artificial bee colony. IEEE transactions on sustainable energy, 2014. 6(1): p. 198-209. 